somewhat similar to that on wound infection. Haemophilus influenzae and Str pneumoniae are the common pathogens involved. Both are highly sensitive to co-trimoxazole and, interestingly, a single dose of co-trimoxazole appeared to provide clinical benefit. This finding is particularly relevant for patients with chronic respiratory disease and warrants further investigation.

The reduction in wound sepsis achieved with co-trimoxazole was significant. Only patients liable to have pathogenic bacteria in their bile at operation have been thought to require antibiotic cover. $^{2}{ }^{7}$ Several methods have been described wherreby such patients might be recognised. These include identifying risk factors, using duodenal intubation, and intraoperative Gram staining. ${ }^{2}$ Few centres, however, have time and resources for these measures. A single dose of co-trimoxazole covering the operative period provides a practical alternative. This reduces not only wound sepsis but also pulmonary complications.

We thank the members of the surgical division, Victoria Infirmary, Glasgow, for co-operating in this study, and Miss I K Morton, chief pharmacist, for randomising the patients. The co-trimoxazole was kindly provided by the Wellcome Foundation Ltd, and the assays were performed by Miss P E Pelham of the Wellcome Research Laboratories.

Requests for reprints should be addressed to: $\mathrm{Dr} \mathrm{W}$ McNaught, Bacteriology Department, Victoria Infirmary, Glasgow G42 9TY.

\section{References}

${ }^{1}$ Edlund, Y, Mollstedt, B O, and Ouchterlony, O, Acta Chirurgica Scandinavica, 1959, 116, 46

2 Keighley, M R B, Annals of the Royal College of Surgeons of England, W $1977,59,328$.

3 Lancet, 1960, 2, 659.

4 Robson, M C, Bogart, J C, and Heggers, J P, Surgery, 1970, 68, 471.

5 Chetlin, S H, and Elliott, D W, Archives of Surgery, 1971, 102, 303.

6 Keighley, M R B, Flinn, R, and Alexander-Williams, J, British fournal of Surgery, 1976, 63, 528 .

7 Gunn, A A, British fournal of Surgery, 1976, 63, 627.

${ }^{8}$ British Medical fournal, 1977, 2, 1500.

9 Annals of Surgery, 1964, 160, suppl No 2, p 22.

10 Cowan, S T, and Steel, K J, Manual for the Identification of Medical Bacteria. London, Cambridge University Press, 1974.

11 Pelham, P E, Bioassay of Trimethoprim, Wellcome Research Laboratories, ขึ 1975.

12 Bratton, A C, and Marshall, E K, fournal of Biological Chemistry, 1939, $\vec{\circ}$ 128, 537.

${ }^{13}$ Keighley, M R B, et al, British fournal of Surgery, 1975, 62, 275.

14 Keighley, M R B, et al, Gut, 1976, 17, 495.

15 Garrod, L P, British Medical fournal, 1972, 4, 473.

16 Burke, J F, Surgery, 1961, 50, 161.

17 Stone, H H, et al, Annals of Surgery, 1976, 184, 443.

18 Stokes, E J, et al, British fournal of Surgery, 1974, 61, 739.

19 Griffiths, D A, et al, Lancet, 1976, 2, 325.

${ }^{20}$ Ross, D J, et al, British fournal of Surgery. In press.

21 Strachan, C J L, et al, British Medical fournal, 1977, 1, 1254.

22 Bushby, S R M, Postgraduate Medical fournal, 1969, suppl No 45, p 10. 요

(Accepted 5 fune 1978)

\title{
Epidemiology of adverse drug reactions to phenformin and metformin
}

\author{
ULF BERGMAN, GUNNAR BOMAN, BENGT-ERIK WIHOLM
}

British Medical fournal, 1978, 2, 464-466

\section{Summary and conclusions}

Adverse drug reactions (ADRs) to phenformin and metformin reported to the Swedish Adverse Drug Reaction Committee during 1965-77 were analysed in relation to sales and prescription data. The biguanides accounted for $0.6 \%$ of all reported adverse drug reactions but for $6 \%$ of the fatal cases (all phenformin). Sixty-four ADRs to phenformin and eight to metformin were classified as causal relation "probable" or "not excluded." Fifty-one of these reactions $(71 \%)$ were lactic acidosis, all but one being reactions to phenformin. After 1973 phenformin was prescribed less in Sweden and metformin became predominant. A nationwide prescription survey during 1975-6 disclosed no differences in age and sex between patients receiving phenformin and metformin. The mean daily doses prescribed in 1976 were $74 \mathrm{mg}$ of phenformin and $1.5 \mathrm{~g}$ of metformin.

The numbers of ADRs to the two drugs reported during

\footnotetext{
Department of Clinical Pharmacology, Karolinska Institutet, Huddinge University Hospital, S-141 86 Huddinge, Sweden ULF BERGMAN, $M D$, research assistant BENGT-ERIK WIHOLM, MD, research fellow
}

Pharmacotherapeutic Division, Department of Drugs, National

Board of Health and Welfare, S-751 25 Uppsala, Sweden GUNNAR BOMAN, MD, associate professor
1975-7 were related to use. The relative incidences of ADRs reported for phenformin and metformin did not differ. Significantly more cases of lactic acidosis and deaths were reported for phenformin.

\section{Introduction}

Biguanides affect lactate metabolism, ${ }^{1}$ and several ${ }^{12}$ but not all ${ }^{3}$ workers have found that phenformin is more potent than metformin. In most reported cases of lactic acidosis the patients $\tilde{\sigma}$ had been treated with phenformin; few had received metformin $D$ or buformin. ${ }^{1}$ This may reflect differences in the use of the drugs rather than true pharmacological differences. A sixfold variation $N$ was found in the total use of biguanides in seven European $\underset{\mathrm{N}}{\mathrm{N}}$ countries. ${ }^{4}$ Phenformin was the most-prescribed biguanide in five of these.

In our study, carried out in Sweden, we attempted to relate reports of adverse reactions (ADRs) to phenformin and met- $\stackrel{\$}{+}$ formin (the two biguanides sold in Sweden) to sales and prescription data.

\section{Materials and methods}

All reports sent to the Swedish Adverse Drug Reaction Committee 8 are scrutinised by a medical officer, discussed by a working party, and settled by the full committee. ${ }^{5}$ In severe cases the complete medical record is obtained. The following classification is used by the committee: causal relation "probable," "not excluded," or "unlikely," or insufficient information available. Only one adverse reaction per person (the most severe) was included in this study. In 1975 it became obligatory to report suspicions of ADRs to drugs that were fatal or 
otherwise serious, new, unexpected, or remarkable. Sales of biguanides in Sweden (Swedish Pharmaceutical Data LSAB) were converted to defined daily doses (DDD). ${ }^{4}$ In a continuous nationwide prescription survey the name of the drug, age and sex of the recipient (since 1974), and prescribed daily dose (since 1976) are recorded in a 1-in-288 sample of all purchases. ${ }^{6}$

We tested differences between means with Student's $t$ test, and between distributions with the $\chi^{2}$ method or binomial distribution.

\section{Results}

Ninety-one suspected ADRs to biguanides were reported in 196577. Seventy-two $(79 \%)$ were classified as probable or not excluded (table I). In 43 cases $(47 \%$ ) the patients were men. Fifty-seven reports were of lactic acidosis; 51 of these were classified as probable or not excluded. In 36 cases, suspected reactions to phenformin, the outcome was fatal. In 22 of these the deaths had a probable or not excluded relation to the ADR, and 19 were due to lactic acidosis. The first ADR to metformin was reported in 1973, and eight of the 13 reports for this drug were classified as probable or not excluded.

TABLE I-Adverse reactions to phenformin and metformin in Sweden during 1965-77 classified as causal relation "probable" or "not excluded"

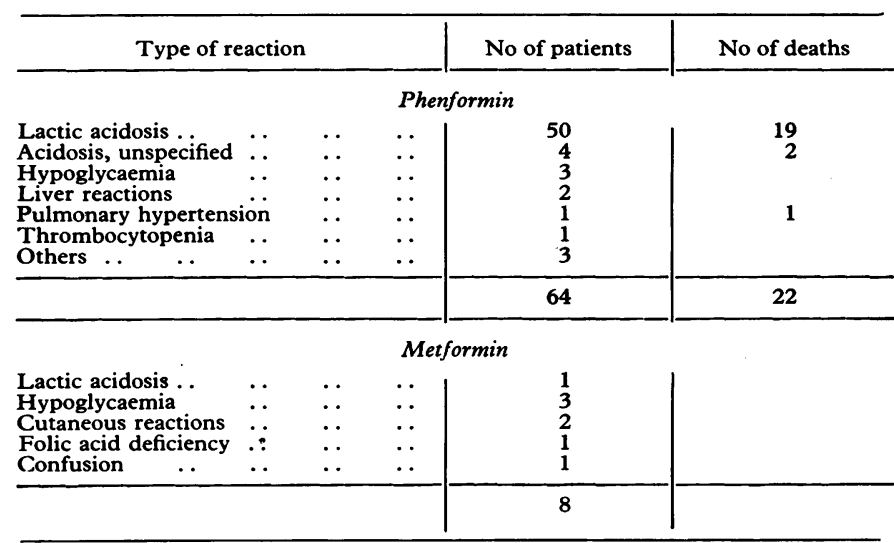

Since late 1976 more metformin than phenformin has been sold (table II). The prescription survey did not show any differences in age or sex distribution between patients receiving phenformin and those receiving metformin (figure). The mean daily dose of metformin ( \pm SD) was $1.5 \pm 0.6 \mathrm{~g}$ (167 prescriptions), while that of phenformin was $74 \pm 25 \mathrm{mg}$ (141 prescriptions). The 13 patients with suspected ADRs to metformin were prescribed the same mean daily dose $(1.5 \pm 0.8 \mathrm{~g})$ as patients in the prescription survey but were significantly older $(72 \cdot 1 \pm 12 \cdot 7$ years $v 63.5 \pm 12 \cdot 8$ years; $P<0.02)$. The 78 patients with reported ARs to phenformin were prescribed a mean daily dose of $94 \pm 30 \mathrm{mg}(\mathrm{n}=74)$, which was significantly higher $(P<0.001)$ than that prescribed in the prescription survey, but they were of the same mean age $(63.4 \pm 15.9$ years $v 63.9 \pm 12 \cdot 1$ years $)$. The same relations were found for patients with lactic acidosis $(95 \pm 29 \mathrm{mg} ; \mathrm{P}<0.001)$ and those who died ( $98 \pm 29 \mathrm{mg} ; \mathrm{P}<0.001)$.

During 1975-7 there was no significant difference between phenformin and metformin in the incidence of ADRs related to sales (table III). There were, however, significantly more reports of lactic acidosis $(P<0.01)$ and deaths $(P<0.02)$ for phenformin. The incidences of reports of lactic acidosis classified as probable or not excluded were 1.76 and 0.13 per million DDDs of phenformin and metformin respectively $(P<0.001)$.

TABLE II-Sales of biguanides in Sweden during 1971-7 in number of defined daily doses (DDDs)/1000 population/day

\begin{tabular}{ll|l|l|l|l|l|l|l}
\hline & 1971 & 1972 & 1973 & 1974 & 1975 & 1976 & 1977 \\
\hline $\begin{array}{llll}\text { Phenformin* } \\
\text { Metformin† }\end{array}$ & $\cdots$ & $\begin{array}{l}2.30 \\
0.19\end{array}$ & $\begin{array}{l}2.32 \\
0.18\end{array}$ & $\begin{array}{c}2.19 \\
0.19\end{array}$ & $\begin{array}{c}1.67 \\
0.34\end{array}$ & $\begin{array}{c}1.02 \\
0.60\end{array}$ & $\begin{array}{l}0.88 \\
0.85\end{array}$ & $\begin{array}{l}0.55 \\
1.04\end{array}$ \\
\hline
\end{tabular}

*Registered 1961; DDD $=0.1 \mathrm{~g}$.
†Registered $1965 ; \mathrm{DDD}=2 \cdot 0 \mathrm{~g}$.

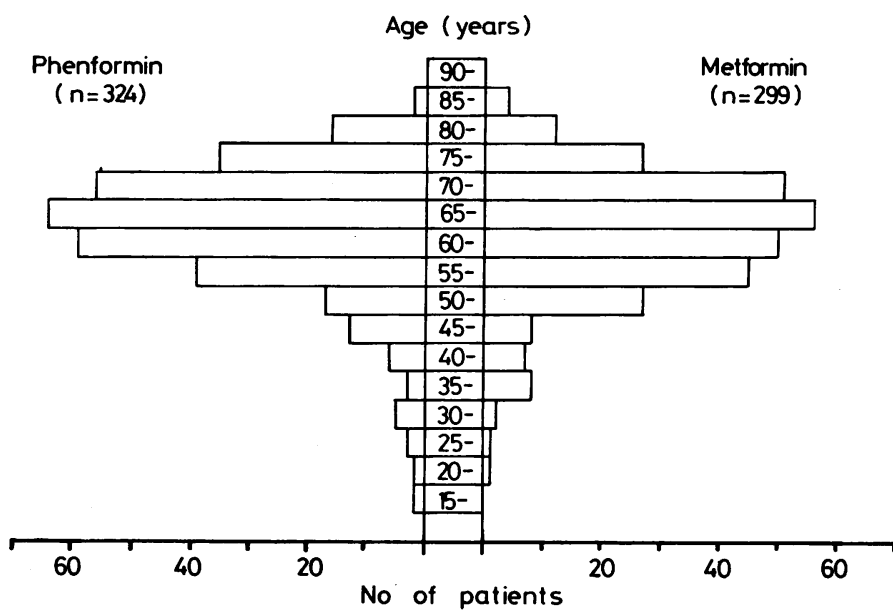

Age distribution of patients receiving phenformin and metformin during 1975-6.

TABLE III-Numbers of adverse reactions to phenformin and metformin reported in Sweden during 1975-7 and relation to sales

\begin{tabular}{|c|c|c|c|c|}
\hline & & Phenformin & Metformin & $\mathbf{P}$ \\
\hline $\begin{array}{l}\text { Sales }\left(\times 10^{6} \text { DDDs }\right) \\
\text { Adverse reactions: } \\
\text { Reported } \ldots \\
\text { Probable and not excluded } \\
\text { Lactic acidosis: } \\
\quad \text { Reported } \ldots \\
\text { Probable and not excluded } \\
\text { Fatal reactions: } \\
\quad \text { Reported } . . \\
\text { Probable and not excluded }\end{array}$ & $\begin{array}{l}\cdots \\
\cdots \\
\cdots \\
\cdots \\
\cdots\end{array}$ & $\begin{array}{l}7 \cdot 37 \\
16 \\
14 \\
13 \\
13 \\
6 \\
6\end{array}$ & $\begin{array}{c}7 \cdot 50 \\
12 \\
7 \\
2 \\
1\end{array}$ & $\begin{array}{l}\text { NS* } \\
\text { NS* } \\
0.01 \dagger \\
0.001 \dagger \\
0.02 \dagger \\
0.02 \dagger\end{array}$ \\
\hline
\end{tabular}

DDD $=$ Defined daily dose. NS $=$ Not significant.

${ }^{*} \chi^{2}$ test. $†$ Binomial test.

\section{Discussion}

Of all suspected ADRs to drugs reported in Sweden in 1965-77 the biguanides accounted for only $0 \cdot 6 \%(91 / 15500)$, but phenformin was used in $6 \%(22 / 360)$ of the cases in which the patient died and the reaction was classified as probable or not excluded. In most of these cases (19 of the 22) the reaction was lactic acidosis. Two of the proposed mechanisms for the hypoglycaemic effects of the biguanides-namely, increased glycolysis and decreased glyconeogenesis $\mathbf{1}$-interfere with lactate metabolism. In controlled studies on diabetics no significant difference was found in the rise in lactate concentration after a glucose tolerance test during treatment with phenformin or metformin. ${ }^{3}$ Moreover, mean 12-hour lactate concentrations, though not fasting values, were raised significantly higher with phenformin than metformin. ${ }^{2}$ Among diabetic patients with poor control, however, those receiving phenformin had significantly higher lactate concentrations than those receiving metformin when admitted to hospital.?

Phenformin and metformin were registered in Sweden in 1961 and 1965 respectively. Several reports of lactic acidosis associated with phenformin treatment were published in Sweden in 1969-73, when metformin was little used (table II). After these reports the indications for both phenformin and metformin were restricted and the contraindications clearly stated. As a result the biguanides were used less and metformin was preferred to phenformin. With this change in use the number of ADRs to metformin increased while that to phenformin decreased. In 1976 no cases of lactic acidosis were reported, which was interpreted as indicating better selection of patients. In 1977, however, six cases were reported, four of which were fatal. The number of cases of lactic acidosis related to the use of phen- 
formin has not decreased (1.63/million DDDs in 1972-4 and $1 \cdot 76 /$ million DDDs in 1975-7).

Previous studies have shown that about $30 \%$ of serious ADRs to drugs were reported to the Swedish committee. ${ }^{5}$ Although the total number of reports has increased since its inception in 1965, reports of death have been fairly constant. ${ }^{5} 8$ This has been interpreted as showing that serious reactions, especially fatal ones, are overrepresented in the reports. The total numbers of reports of ADRs to metformin and phenformin are of the same order when related to use (table III), which speaks against a serious reporting bias. Furthermore, age and sex aistributions in the prescription sample were similar for the two drugs, as were the prescribed daily doses versus the respective DDDs. Metformin is eliminated by the kidneys while phenformin is also metabolised. ${ }^{1}$ Accordingly, the daily dose of phenformin and the age of patients receiving metformin seem to be important factors in the development of ADRs to the drugs. An age limit of 60 years for biguanide use would have eliminated $70 \%$ of the patients treated (figure) and 78\% (40/51) of the cases of lactic acidosis classified as probable or not excluded. The youngest patient with lactic acidosis was only 20 years old.

Our findings indicate that this methodology is valuable for comparing the incidences of ADRs to similar drugs. Since ADRs are underreported, ${ }^{5}$ however, these figures should not be extra- polated to "true" incidences. Our study also indicates that phenformin is more likely than metformin to cause lactic acidosis. This is a clinical advantage for metformin under the premise that both drugs are equally effective.

This study was supported by a grant from the Karolinska Institutet. $\frac{1}{1}$ We are indebted to the National Corporation of Swedish Pharmacies $\cong$ for providing material from their prescription survey. We also thank $\subseteq$ $\mathrm{Mr}$ Staffan Ekblom, of the statistical research group, Stockholm $\overrightarrow{\vec{F}}$ University, for evaluating the statistical methods used.

\section{References}

1 Alberti, K G M M, and Nattrass, M, Lancet, 1977, 2, 25.

2 Natrass, M, et al, Diabetologia, 1977, 13, 145.

3 Alexander, W D, and Marples, J, Lancet, 1977, 1, 191.

Bergman, U, in Drug Utilization Studies Methods and Applications, ed U Bergman, A Grimsson, and B Westerholm. Copenhagen, World Health Organisation, Regional Office for Europe. In press.

${ }^{5}$ Böttiger, L E, et al, fournal of Clinical Pharmacology, 1974, 14, 401.

${ }^{6}$ Kristoferson, K, and Wessling, A, Svensk Farmaceutisk Tidskrift, 1977, $\mathbf{8 1}, 309$.

7 Luyckx, A, et al, fournées Annuelles de Diabetologie Hôtel-Dieu, 1974, p 129. స̃

8 Böttiger, L E, Furhoff, A-K, and Holmberg, L, Läkartidningen, 1977, 74, 1182 .

(Accepted 26 May 1978)

\title{
Spontaneous milk ejection during lactation and its possible relevance to success of breast-feeding
}

\author{
ALAN S MCNEILLY, JUDITH R MCNEILLY
}

British Medical fournal, 1978, 2, 466-468

\section{Summary and conclusions}

In a woman suckling twins it became apparent that both suckling-induced and precisely timed, spontaneous bursts of milk ejection were occurring. Observations on days 14, 28, 56, and 112 of lactation disclosed highly significant increases in intervals between episodes of spontaneous milk ejection. Furthermore, at all stages of lactation the interval between a feed and the next episode of spontaneous ejection was significantly longer than the interval between spontaneous ejections.

The decrease in frequency of episodes of spontaneous milk ejection during lactation may be related to the decreasing release of prolactin in response to suckling. Spontaneous milk-ejection episodes are felt only when the breast is full and may signal its readiness for a further suckling episode. Such bursts of milk ejection may stimulate the suckling response in babies, suggesting that rigid three- or four-hour feeding regimens may be unphysiological and pose a threat to the success of breastfeeding in the early postnatal period.

MRC Unit of Reproduction Biology, Edinburgh EH1 2QW ALAN S MCNEILLY, PHD, research scientist JUDITH R MCNEILLY, PHD, physiologist

\section{Introduction}

In recent years there has been a resurgence of interest in breast feeding. An increasing number of women start to breast-feed: their babies, but while many continue to breast-feed for severals months a large proportion stop within a few weeks of leaving hospital. ${ }^{2}$ The reasons for stopping breast-feeding are many윽 and varied but we do not know how often it is due to failure or: inadequacy of normal physiological mechanisms. ${ }^{2}$ Lactationo comprises two separate physiological mechanisms-namely, milk secretion, which is controlled by prolactin released from? the anterior pituitary in response to the suckling stimulus; andN milk ejection, a neuroendocrine reflex in which oxytocin released from the posterior pituitary in response to sucklingo causes contraction of the alveoli of the breast and ejection of milk via the mammary ducts and nipple. Whereas the role of prolactin in lactation has received much attention, ${ }^{3-5}$ that of oxytocin and the factors controlling milk ejection have been? virtually ignored..$^{6-10}$

Milk ejection during suckling may be inhibited by both physical and psychological stress, and women are more ${ }^{+}$ susceptible to these stresses during early lactation. ${ }^{11}$ Newton and ${ }_{\vec{O}}$ Newton's ${ }^{11}{ }^{12}$ classical study also showed that successful breast- $\frac{0}{\mathbb{D}}$ feeders exhibit a greater milk-ejection response to suckling than $\frac{\rho}{\Phi}$ unsuccessful breast-feeders, again emphasising the importance of oxytocin release in the success of breast-feeding.

Oxytocin release occurs in response not only to stimulation of the nipple during suckling ${ }^{8}{ }^{9}$ but also to other factors associated with breast-feeding-for example, the cry of the baby. ${ }^{6}{ }^{710}$ In addition, in anaesthetised rats, whose young are continually on the nipples, oxytocin release appears to occur spontaneously at precisely timed intervals independent of any suckling stimulus; the pups suckle only after spontaneous milk ejection has 